\title{
A FIELD GUIDE TO SONIC BOTANY: THOUGHTS ABOUT ECO-COMPOSITION
}

\author{
Maayan Tsadka
}

\begin{abstract}
Sonic botany is an ongoing project that I have been developing over the past few years. It incorporates natural artefacts: dry leaves, pods, flowers, branches, rocks, bones and other organic findings. These are used as musical instruments that are played on with a scientific/musical tool: tuning forks in various frequencies. The vibration from the tuning forks resonates through the natural artefacts which amplify the vibration and - via sound reveal the texture, size, material and condition of the organic matter. This process generates new sonic material, new context and new forms of musical composition. The practice developed into several compositions and projects, a performance practice, a notation system and a way of listening. Here I share some of the insights I gained through this process, the tools and the compositional framework.
\end{abstract}

\section{Background}

Sonic botany was born the day I noticed that a dry Echeveria Gibbiflora leaf somewhat resembles the ear of a bat (see Figure 1) - the shape, the detailed veins, the terrain. It got me thinking about the leaf/ plant as an ear: noticing how the shape of a flower, a pod or a leaf is perhaps partially designed to absorb and direct sound into it. What is it like to 'hear' the world from a plant perspective? This thought was the beginning of an ongoing attempt to step outside our human perception and experience, or imagine, at least, the world from other perspectives. The plant is not only an ear, however, but also a speaker: a vibrating membrane, a means of natural amplification. Each plant, or part of it, has embedded organic information that can be carried and reflected through sound. Exploring every leaf and artefact as a micro-landscape is a way to generate and create new soundscapes derived from those sonic materials. In a close listening one can notice the small details, texture, shape and condition of the artefacts.

My tools and method for this exploration is a direct and controlled vibration: tuning forks in various frequencies (see Figures $2 \mathrm{a}$ and $2 \mathrm{~b}$ ). During this process, whether practising at home or in a performance situation, I keep in mind this duality of the leaf as an ear on the one hand, and the leaf as a speaker on the other. Not only does it absorb the sonic information, but it also transforms it. 
Figure 1:

Dry Echeveria Gibbiflora leaf.

Figure 2a:

Sonic botany: tools (photo by MUPERPHOTO).

Figure 2b:

Sonic botany: artefacts (photo by MUPERPHOTO).
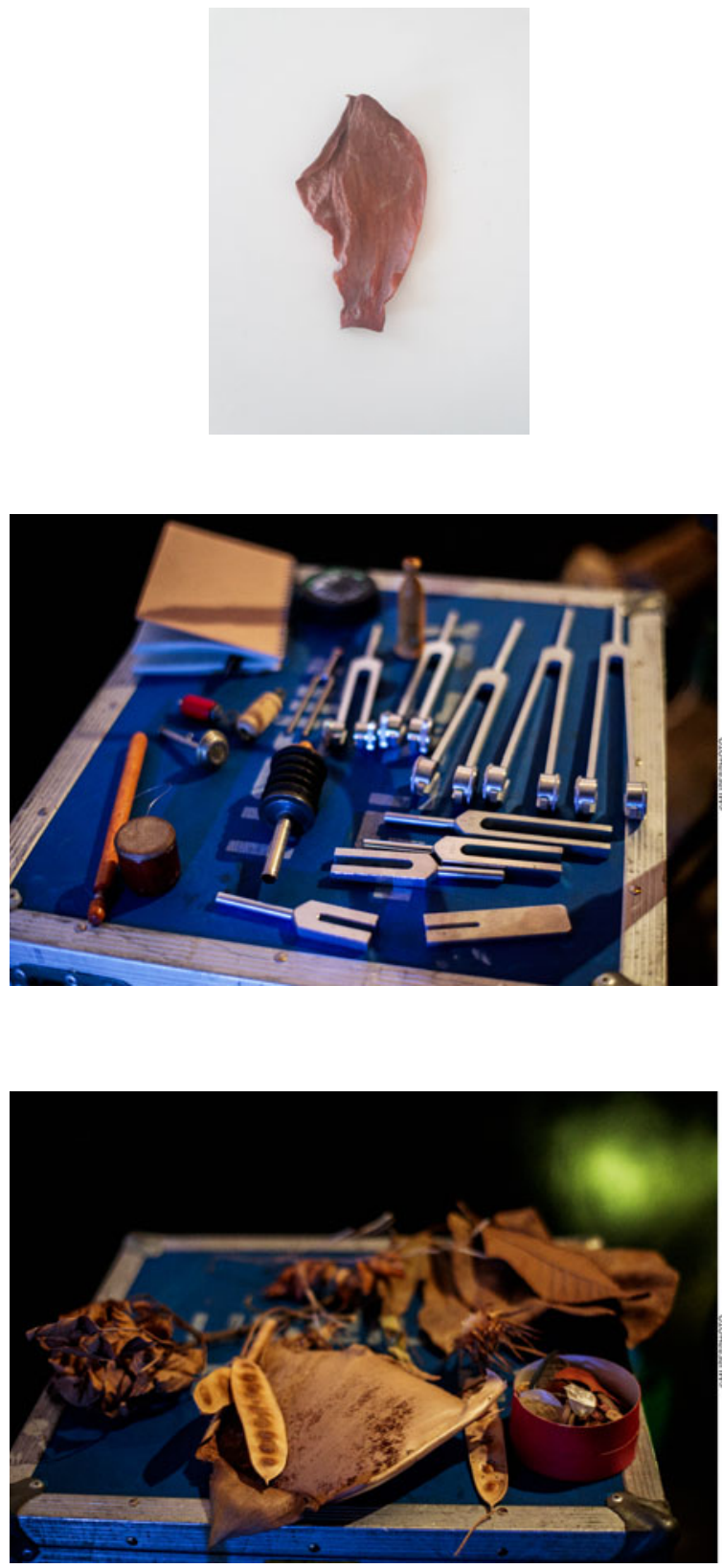

It is hard not to think of the early days of sound recording devices, and the interesting similarities in shape and design between the phonograph or phonautograph bell (and later the gramophone) and the shape of a flower, where the stamen functions as the needle, picking up the vibrations, and the petals functions as a bell, directing the sound inwards (see Figures $3 \mathrm{a}$ and $3 \mathrm{~b}$ ).

Plants and other natural artefacts were some of the earliest musical instruments used by humans, whether a hollow papaya branch as a pipe, bamboo sticks as wind or percussion instruments, rattling pods, or a thin leaf vibrating and whistling between one's lips. 
Figure 3a:

Mirabilis Jalapa

\section{Figure $3 \mathrm{~b}$ :}

A gramophone
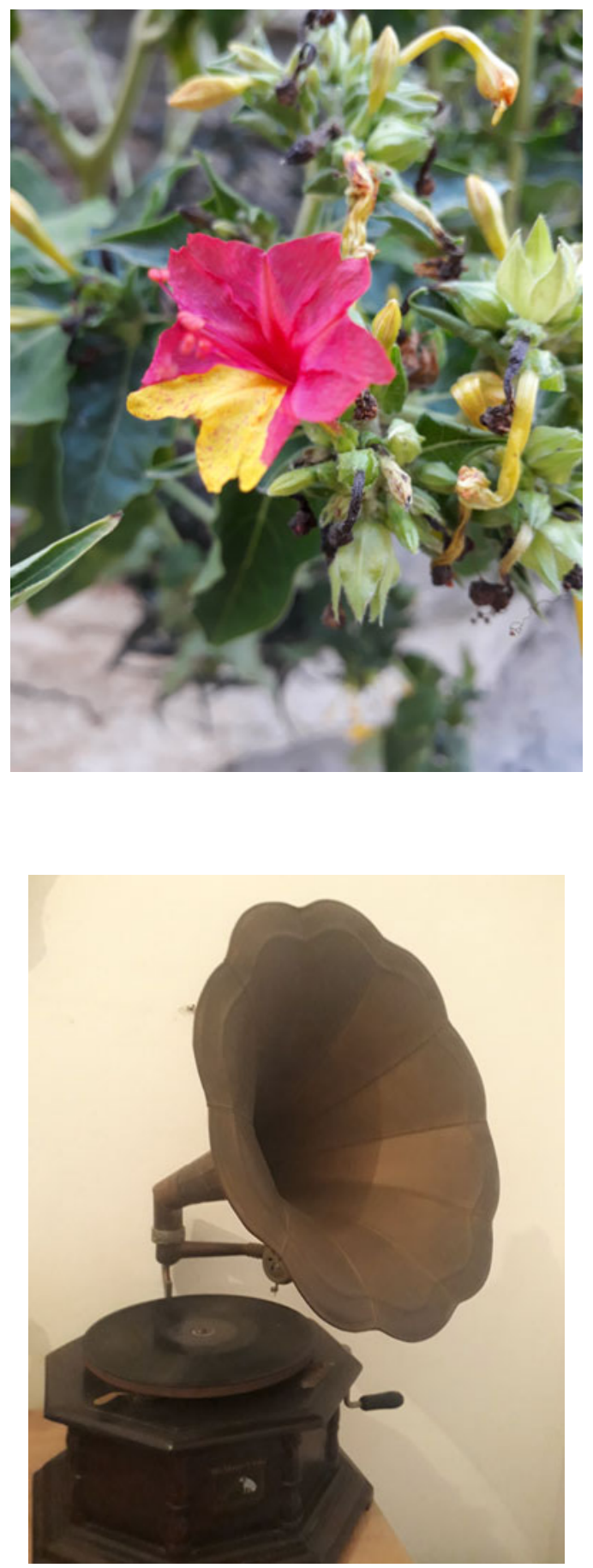

Many of those instruments were used to imitate the sounds of their environment. Since prehistoric days this idea of sonic potential has, of course, been developed and perfected through technological development, musical aesthetics and human imagination. This process of discovering, imitating and mastering the acoustic properties of natural 
artefacts and the environment that surround us is one that fascinates me. It has led me to thinking of and exploring natural objects as resonators in which, rather than amplifying external sound, sounds are used in order to reveal and amplify inherent properties of the object. The focus is not on the sound that is carried through a resonating body but on the sonic and physical qualities of the body itself.

\section{The Tools}

The tools are tuning forks in various frequencies, dry plants and other natural artefacts, and a small electronic device (looper and time stretch).

\section{Tuning Forks}

I've been collecting and working with tuning forks for musical purposes for several years now, but only in this project have they fully manifested themselves as musical instruments. As with any other object used in a musical setting, it is not only the acoustic properties that are taken into account, but also the symbolic meaning and the representation of the object in relation to history: cultural, social and political. The tuning fork - its invention in 1711 usually credited to John Shore - was used as a reliable, uniform tuning device (which in turn gives us an insight into the arbitrary nature of standardisation). Later, in the nineteenth century, it was used both as a scientific and as a clinical tool. Scientifically, its pure and accurate frequency was utilized to measure the speed of sound, to determine frequency and to explore physical acoustic phenomena such as resonance, interference and intervallic ratios, to name but a few. In medical fields it was used in otology to study the anatomy and diseases of the ear, mostly to diagnose hearing disorders through bone-conduction hearing, but also in the field of neurology, with Charcot's infamous experiments on hysteria and other disorders. All of those previous uses of the tuning fork, in the fields of music, science and medicine, served as a reference point, as well as a way to reclaim it in a musical context. The musical setting in which I use tuning forks is inspired by some of these scientific uses and clinical methods, made manifest in a musical aesthetic, composition and live performance.

Secretive Nature: the poetics of tuning forks

One of the aspects that always fascinated me about tuning forks is their seemingly secretive nature, only revealed when in close proximity to the ear, on one's body, or amplified through a surface. It holds a sound energy which is concealed, reserved only for those who know how to unlock it. In Hebrew the word for 'concealed' (אצור) is etymologically connected to the verb 'to create' (ליצור), but also to the word for a 'treasure' (אוצר), and the word describing 'internal, uncontrolled, instinctive urge or passion' (יצר).

The hidden sound is only one aspect of the secretive nature of the tuning fork; tuning forks are also characterised by their short duration resonance. From a listener's perspective, once you understand that the played pattern is very short, the brain needs to adapt to that and pay full attention not to miss this brief sound event. Gradually, over an extended series of repeats, the short life cycle of the tuning fork becomes a whole universe, with a distinct envelope and subtle details embedded in it. The rapid time span of the musical event demands a different listening mode. When slowed down with digital assistance it 
Figure 4:

A natural tuning fork I found along the banks of the River Danube.

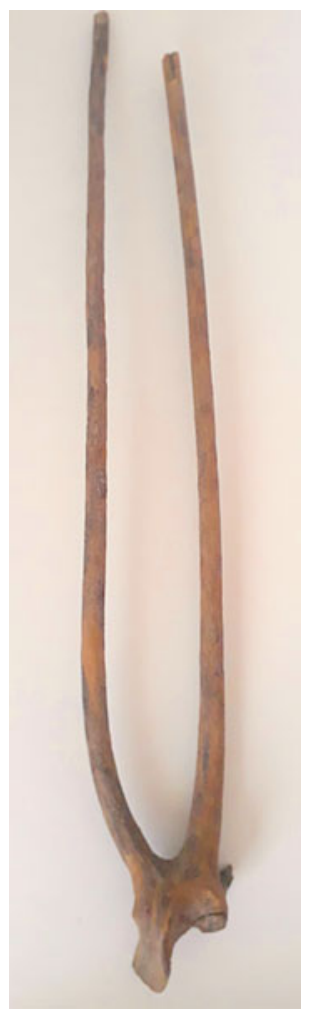

becomes an attempt to listen at a different time scale, not unlike many slowed-down recordings of birds and other animals. Time perception is an important element in these works and is explored by the two extreme poles of the spectrum: on the one hand the short-duration resonance of the tuning fork, and on the other, the augmentation/ diminution of time using electronic devices.

\section{Acoustic Properties}

The acoustic properties of the tuning fork partially shape the aesthetic of the pieces and function as a musical tool borrowing elements and inspiration from the scientific world.

The ability to only use one sound (frequency) at a time, and the quality of 'pure' sound (relatively speaking) narrows the pitch content and allows for greater presence of other musical elements: texture, timbre, rhythm, overtones/undertones. The accurate frequencies allow for a systematic comparison and the range of frequencies (I have forks ranging between $54.81 \mathrm{~Hz}$ and $8000 \mathrm{~Hz}$ ) generates different sonic responses. The need for amplification is embedded in resonance through organic matters: the sound of the tuning fork is filtered through the object and carries some of its physical characteristics. The natural sound envelope of the tuning fork - attack-decay-sustain-release - generates a repetitive sonic cycle, which also requires one to take into account the means of exciting the tuning fork and how to incorporate that as part of the piece.

In terms of harmonics the sonic material ranges between the 'pure' fundamental with occasional overtones, multiphonics and even 
Figure 5a:

Devonian vascular plants (C) 2005, Dennis C. Murphy; used with permission).

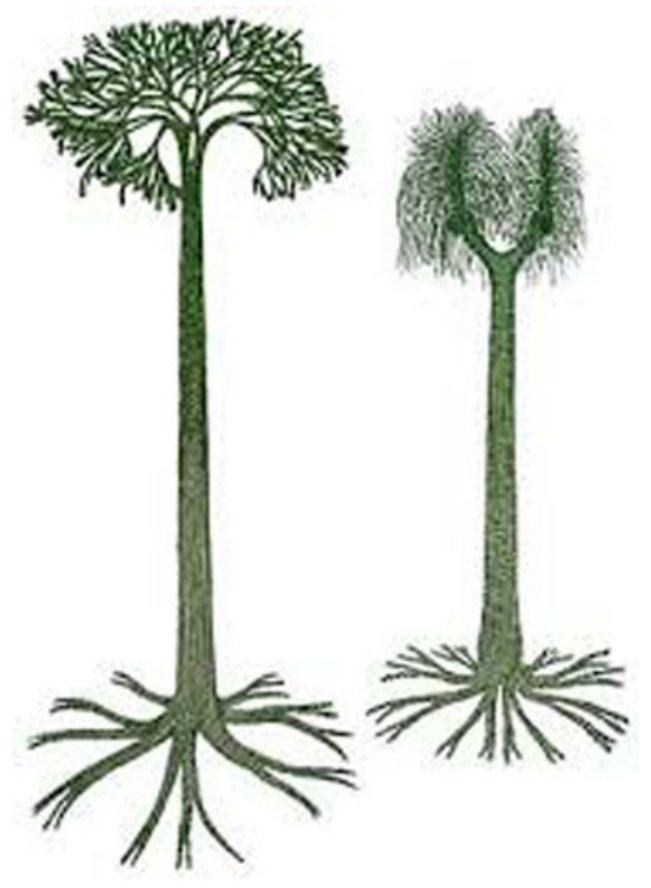

subharmonic tones, which occur in the traction between the tuning fork and the object, depending on the playing technique and the characteristics of the artefact.

Thinking again of design inspired by nature, the shape of the tuning fork can be found everywhere in tree branches (think about all those vibrations going down a tree trunk) (see Figure 4). Plant evolutionary biologist Karl J. Niklas refers to the first vascular land plants from the Devonian period as 'botanical tuning forks' ${ }^{\prime 1}$ (see Figures 5a and 5b).

\section{Plants as Resonators}

The plants are collected from different locations, often from the local surroundings of a specific performance. The process of working with those objects as resonators includes an initial research stage: trying out different frequencies, different playing techniques, exploring the sonic possibilities and mapping the results. Each part of the plant would sound different and respond differently to different frequencies (usually not a specific frequency but rather a frequency range: low-middle-high). When vibrated by a tuning fork, artefacts in different stages of decay will differ in sound. One can hear the Albizia pods rattle, the Thistle thorns buzz, the hollow interiors of the Datura pod, and the thick Ficus veins produce multiphonics. In an augmented setting of my practice in which I add an instrumental ensemble I look for instruments with a mechanism that can somewhat resemble the function of the tuning fork in sending vibration directly through an object. String instruments, particularly the double bass, seem to work in an

\footnotetext{
${ }^{1}$ Karl J. Niklas, 'Plant Physics' Book Talk, on Cornellcast, posted 9 November 2012, www. cornell.edu/video/plant-physics-book-talk.
} 
(a)

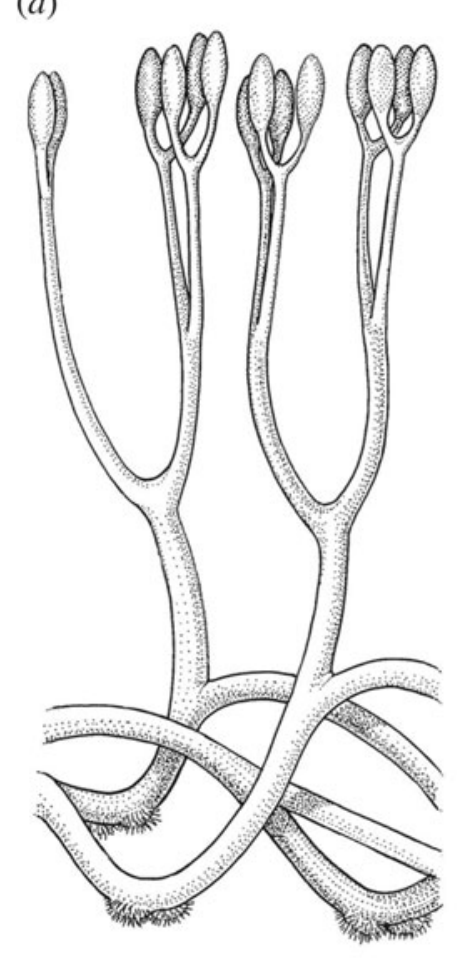

(b)

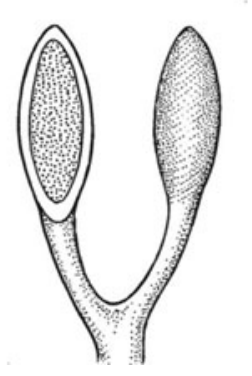

(c)

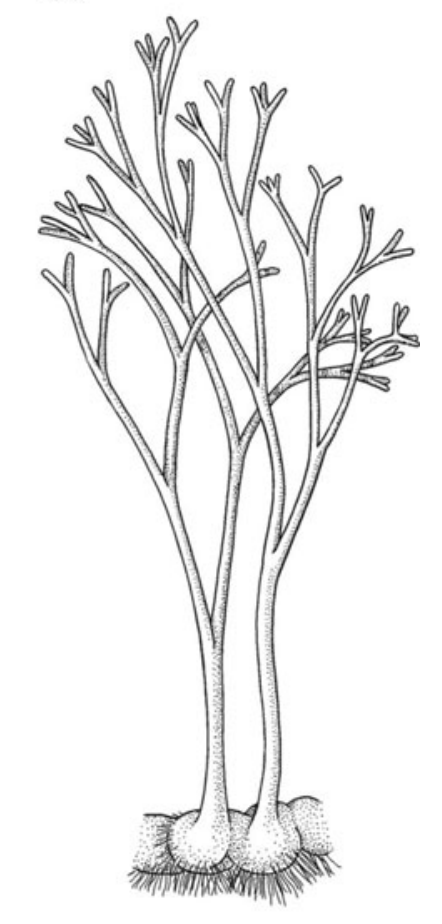

(d)

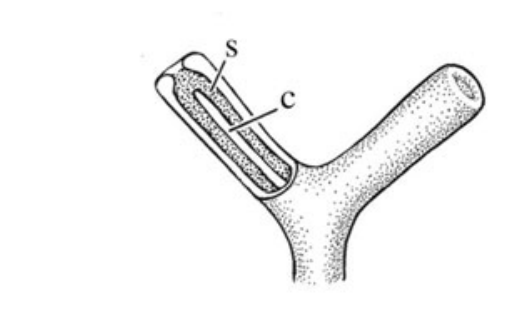

Devonian vascular plants. Paul Kenrick, 'Changing Expressions: a Hypothesis for the Origin of the Vascular Plant Life Cycle',

Philosophical Transactions of the Royal Society B: Biological Sciences, 373, no. 1739, http://doi.org/10.1098/rstb. 2017.0149 , p. 5, Figure 4. Used with permission.

.

interesting way: the pitch of the string is simultaneously amplified through the object (mostly leaves), while the object distorts the sound quality of the instrument. Combining the scientific qualities of the tuning forks with the natural artefacts allows for a systematic comparison: the same artefact played by different tuning forks, or the other way around, the same tuning fork playing on different artefacts. This sonic comparison amplifies the subtle or not-so-subtle differences in the artefacts.

\section{Looper and Time stretch}

In order to grasp some aspect of different time perception, I use time stretch/acceleration to uncover the subtle, hidden worlds of micro sounds. In a performance setting I integrate live playing and live recording, using the looper to create a multi-layered soundscape. 
Figure 6a:

Spectrographic analysis of Lunaria seed pod, $62.64 \mathrm{~Hz}$.
Figure 6b:

Spectrographic analysis of Lunaria seed pod, $440 \mathrm{~Hz}$.
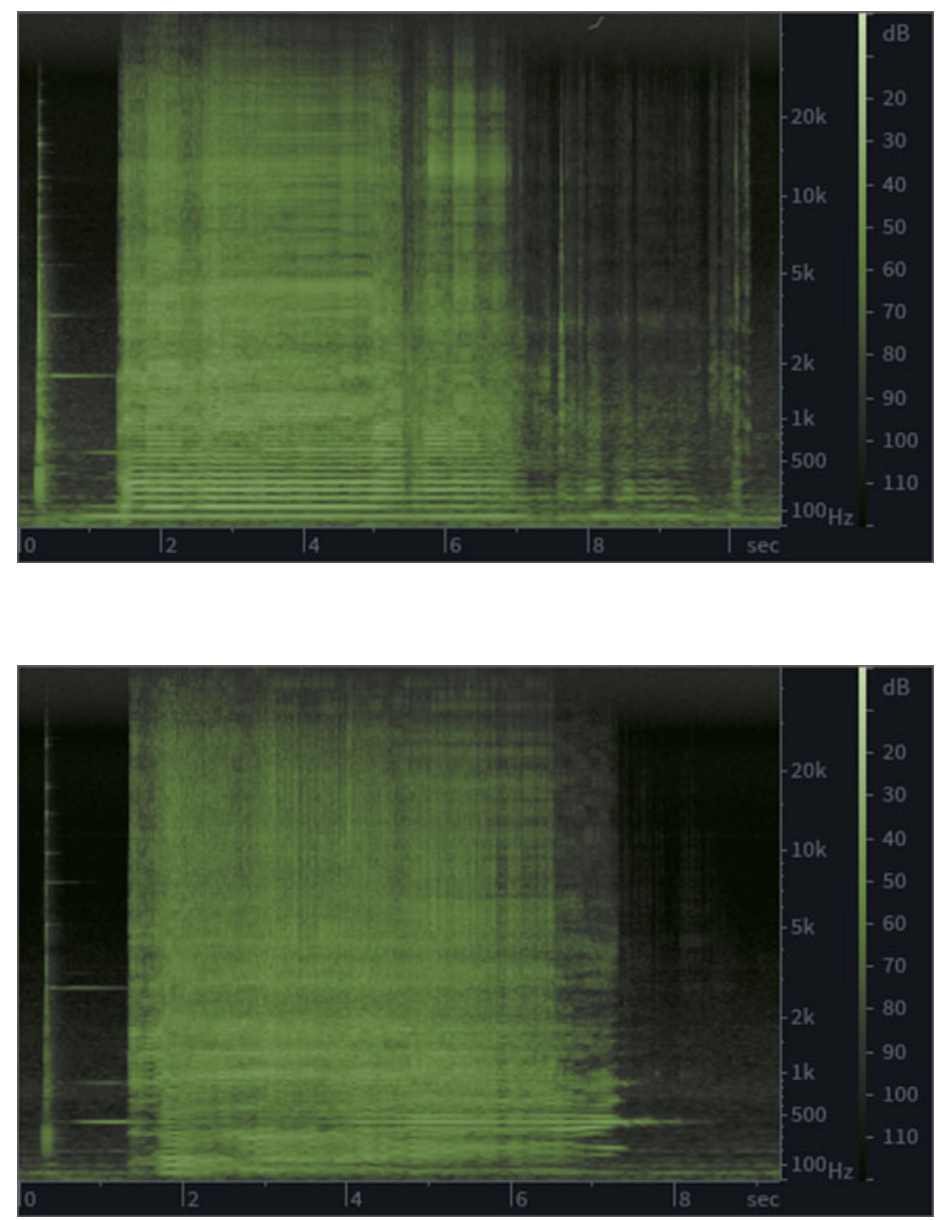

\section{Aesthetic}

In those works I am thinking about musical aesthetics from two different perspectives: one is external and provides a broader, structural and referential context; the other is internal, and dictated and derived from exploring and optimizing the acoustic possibilities of the materials used. The external point of view is shaped by field recordings, natural history books and catalogues, taxonomic systems, botanical research, scientific use of the instruments and imaginary speculative worlds. The internal perspective is derived from the sonic properties of the tuning forks, acoustic behaviours and sound characteristics of the objects used. The systematic nature of this exploration generates a clear musical aesthetic, one which is less linear, more comparative, exposing inherent structures at the micro-level, while also creating new imaginary soundscapes at the macro-level.

\section{Aesthetic of field recordings}

I draw a great deal of inspiration from field recordings - natural and ethnographic - both as a way of listening and a way of documentation. The recordings from the field generate a specific musical aesthetic that is a default of the medium and the circumstances of recording, rather 
Figure 6c:

Spectrographic analysis of Lunaria seed pod, $2048 \mathrm{~Hz}$.
Figure 7:

Sonic Botany performance.
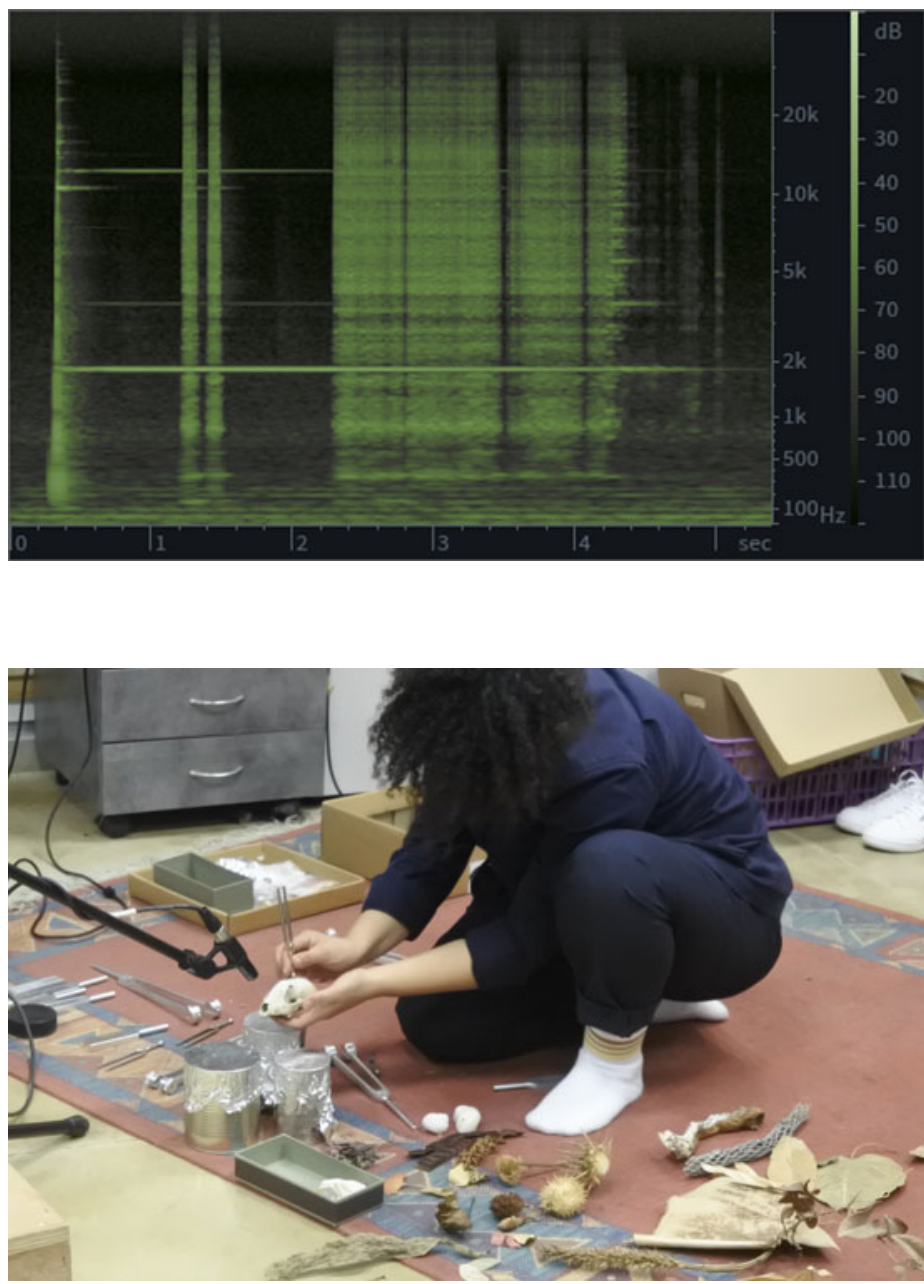

being related to the music itself. The resulting aesthetic takes its character from the technology used (the means of recording and reproduction), the natural conditions and the social situations. I extract certain elements of this aesthetic and apply them in a composed situation. The inherent musical aesthetic I extract from such recordings are short, repeated patterns, systematic comparison, a musical structure which does not necessarily have a linear progression or directionality but rather amplifies inaudible sonic behaviours. The aspect of unpredictability in field recordings is echoed in partially improvised performances, in which the process of creating a soundscape is not determined. For me the act of field recording is, in itself, a way of listening without expectations. I am trying to convey something of this approach in my sonic botany pieces.

The reproduction of those recordings, in the shape of an album, also generates its own aesthetic: because the medium and its function was mostly used in the past for documentation purposes it is presented in a catalogue manner, is often comprised of short audio clips presented as isolated phenomena, and removes its audio material from its original environmental context (see Figures 6a, 
Figure 8:

Amplifikatsija Naturalis EP cover.

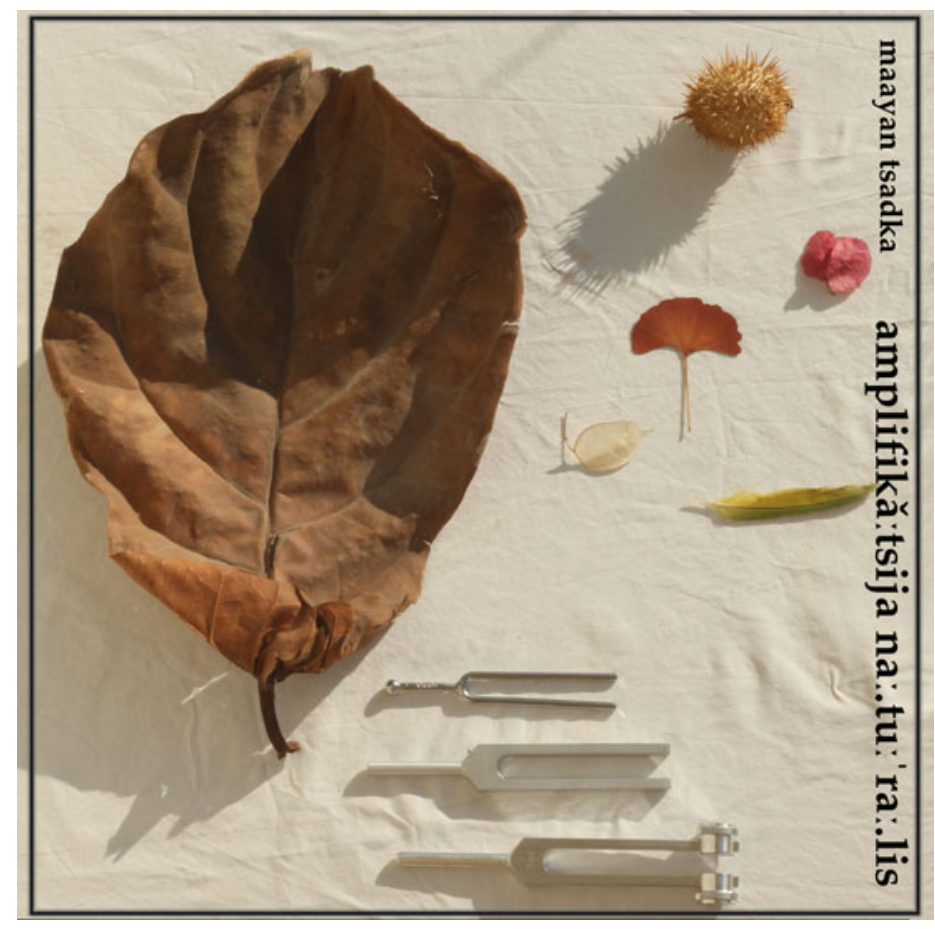

$6 \mathrm{~b}$ and $6 \mathrm{c}$; the recordings can be heard at https://youtu.be/ WzG438ppsu0). When listening to such album recordings one hears ordered audio tracks, which by the virtue of succession alone (but not only) generate a new narrative, and an opportunity for new, comparative observations. From various natural history books I take the process of systematic, unnatural comparison, often of things that would not be able to exist side by side in real life. I am also interested in the way these books allow one to break down and analyse an artefact (be it an animal or a plant) in its smallest components.

Finally, I am making an analogy between the microscope, which allowed for such detailed observations and my use of microphones and time manipulations. The performance of the pieces becomes a sonic exploration of the material, an attempt to share those moments of discovery, the principal performative intention being one of attunement. The pieces move between ordered, systematic and unnatural sonic taxonomies, usually explored as a single event at a time, and the broader assembling of a new multilayered soundscape enabling different time perceptions.

\section{Works}

I will briefly discuss three different works which have evolved from this practice and show how the ideas I have described apply in different musical settings: a solo performance, a recording, and an ensemble piece. The whole process was one of discovery and invention, in which I had to develop new compositional tools, notation system, rehearsal practice, playing techniques and performance practice. 
Figure 9a:

The Vegetable Lamb of Tartary, from Demetrius de la Croix, Connubia Florum (1791).

Figure $9 \mathrm{~b}$ :

'The "Borometz", or 'Scythian Lamb", from Demetrius de la Croix, Connubia Florum (1791).
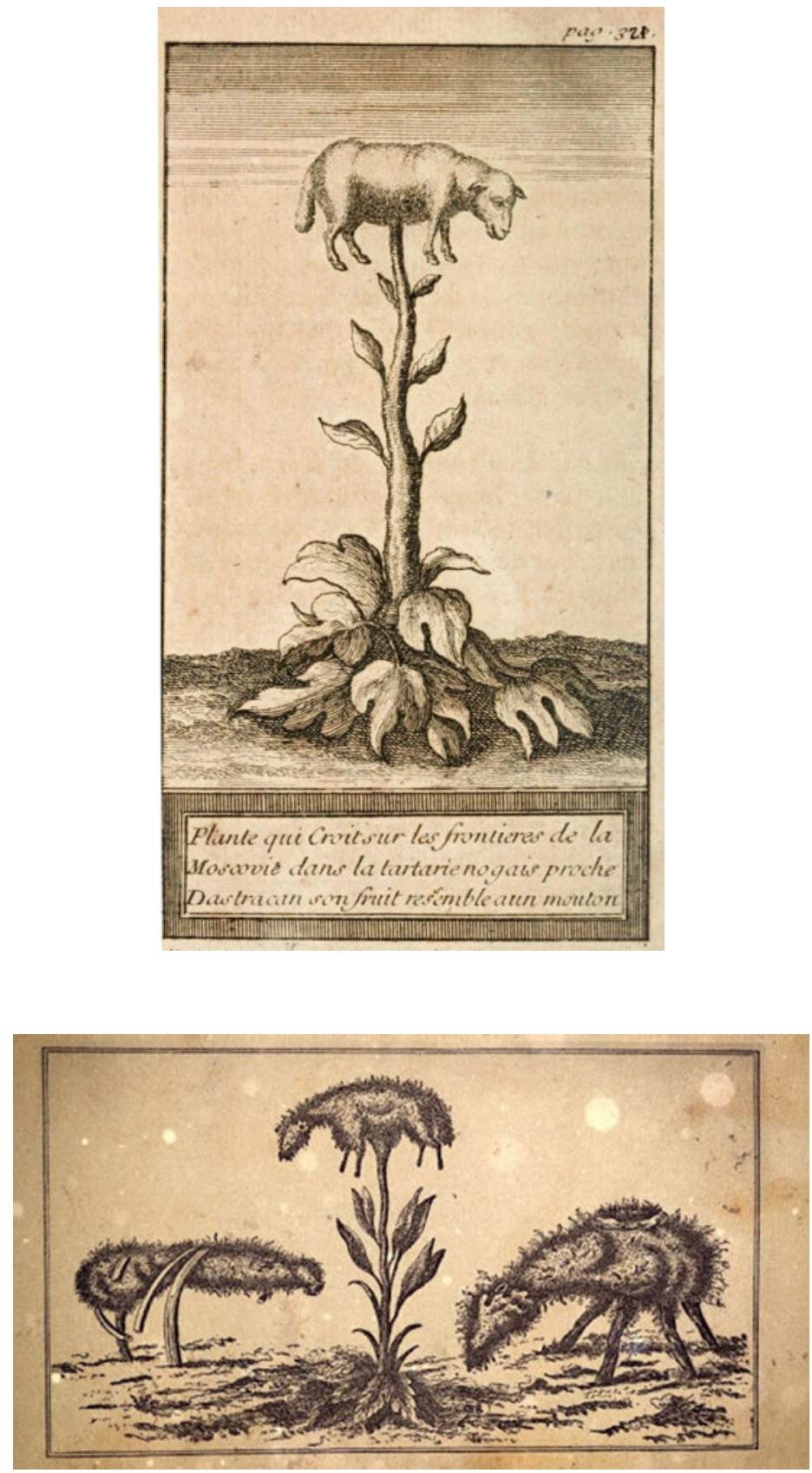

Sonic Botany: a solo performance

The solo performance of the piece is an ongoing process which is changing and growing with every iteration. As I mentioned earlier the artefacts used are often collected from the local surroundings. Structurally the piece starts with a succession of single sonic events exploring the different artefacts, which are gradually accumulated and transformed to create a complex soundscape. The initial exploration of each artefact is systematic and comparative by 
Example 1a:

Maayan Tsadka, 'Insects and Reptiles I', The Vegetable Lamb of Tartary.

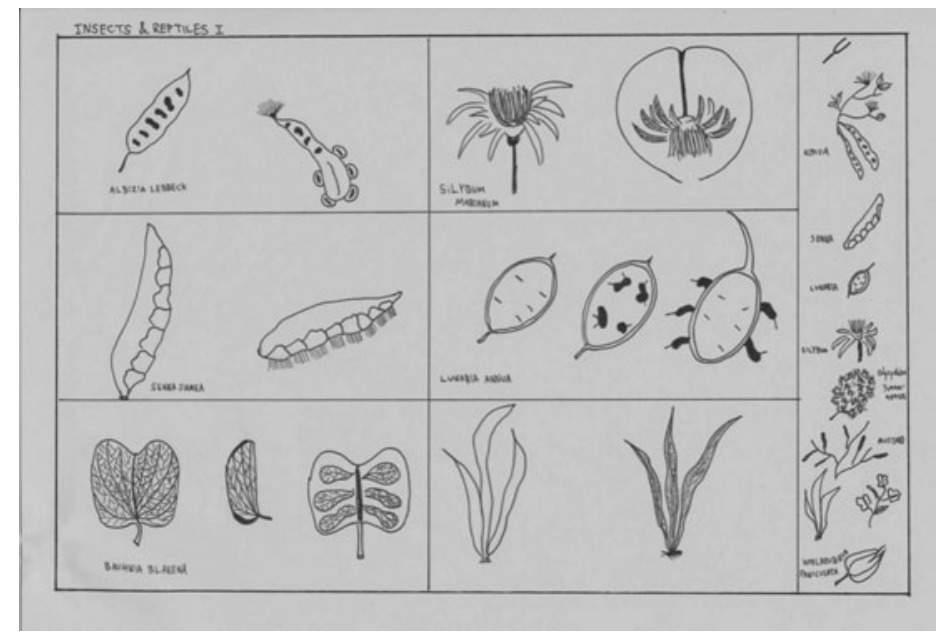

nature, whereas in the second part I incorporate a looper device and time manipulations of the recorded materials to create multilayered textures. I often use this as a mental listening exercise to expand my listening abilities (even if by intention alone) and to experience several different time scales at once: timescapes. With technological assistance I can simulate this idea by layering the live playing with an accelerated/slowed down recording of the same material. This process of time manipulation, combined with repeated musical patterns, is where pods start flying and become wings, thorns transform into nocturnal insects, and leaves become an amphibian chorus.

\section{Amplifikatsija Naturalis: a recording}

This short EP (see Figure 8) was a first attempt to record and capture some of my process. It was recorded with very limited equipment and in a short time (over one weekend) for The Weekend EP Project, initiated by composer Jesse Marino. It is made up of 13 tracks presented in a catalogue-like aesthetic. The systematic comparison utilises tuning forks in only three frequencies, to emphasise the sonic comparison of the artefacts. The materials used are three tuning forks (355.5hz, 440hz and 512hz), Bougainvillea flower, Lunaria seed pod, Psittacula Krameri feather, Ginkgo leaf, Ficus leaf and Marah Macrocarpus seed pod. Tracks 8-13 include a slow-speed version of the recordings.

The Vegetable Lamb of Tartary: an ensemble piece

The vegetable lamb of tartary is a cryptobotanical myth about a plant with lamb growing as fruit (see Figure 9a). A flexible umbilical cord connects the lambs to the ground and allows them a limited movement in order to eat the vegetation around the plant (see Figure 9b).

Most references point to the plants Cibotium Barometz or Gossypium

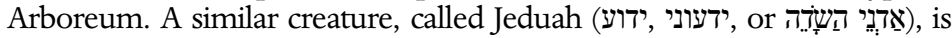
mentioned in the Jewish folklore. Many of the sonic worlds I create with my sonic botany practice are related to and inspired by animal sound communication, real or imaginary, so it was a natural progression to 
Example 1b:

Maayan Tsadka, 'Insects and Reptiles II', The Vegetable Lamb of Tartary.
Example 1c:

Maayan Tsadka, 'Insects and Reptiles III', The Vegetable Lamb of Tartary.
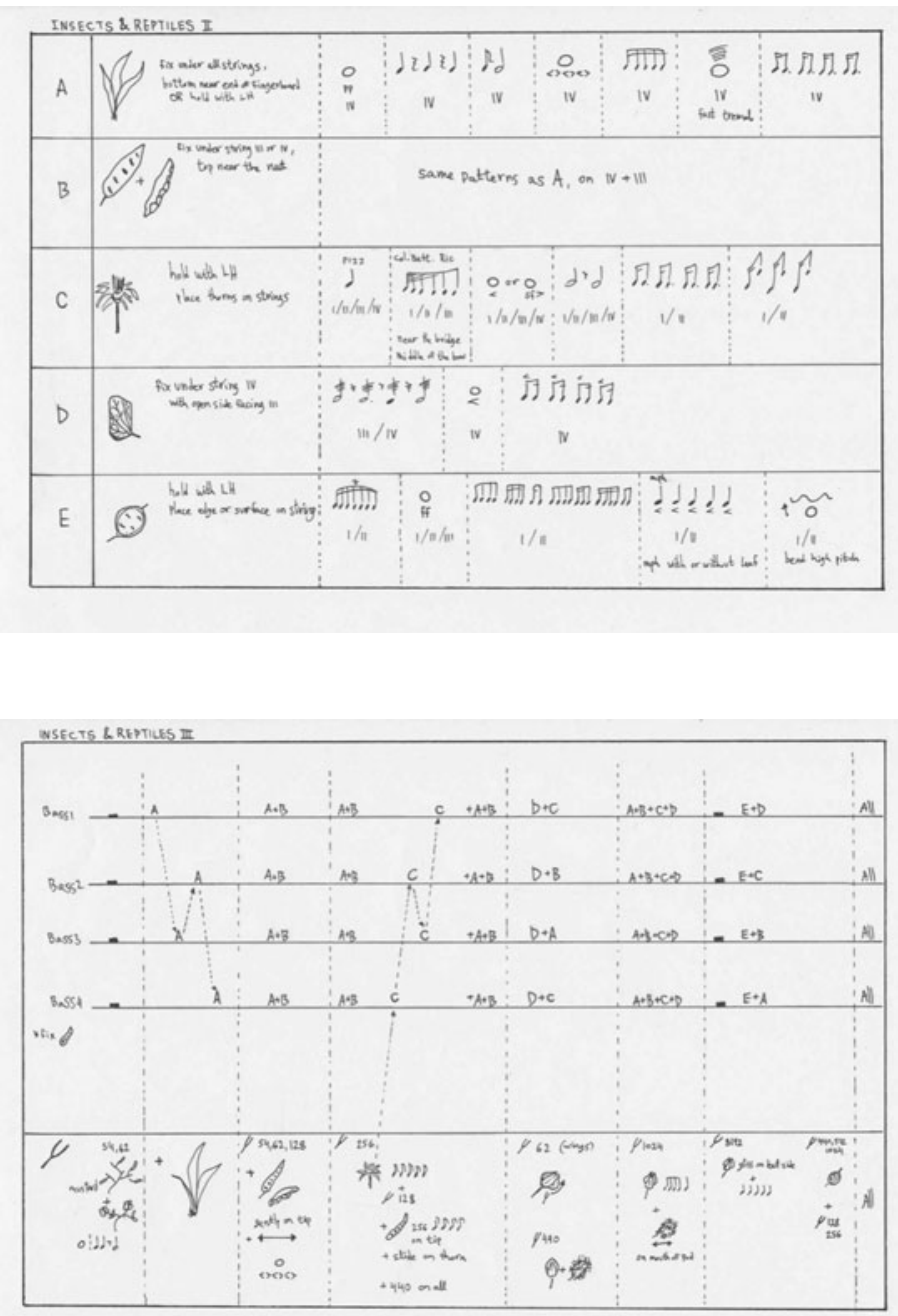

extend those ideas and imagine a world in which a parallel evolutionary process led to the development of hybrid creatures: part-plant, part-animal. This idea was the departure point for the piece, commissioned by the Tzlil Meudkan festival in Tel Aviv and written for four double-basses and leaves, with me performing on tuning forks and various natural artefacts. Inspired by my growing artefact collection I invented a series of hybrid creatures, each with unique sonic features that are related to and derived from the actual leaf I was using. This sonic world is presented in what I like to think of as 'field recordings from a parallel world'. The hybrid creatures are ordered according to five categories: large mammals, insects and reptiles, deep sea, amphibians, avians.

\section{Notation System}

While sonic botany was a personal practice that I was performing on my own there was no need for a clear notation system. This piece gave me the opportunity to think about this practice in relation to 
notation and develop a new system. The score is itself visually inspired by natural history books and it includes visual representation of the hybrid creatures, practical information about the placement of the leaf in/on the instrument, playing instructions, and rhythmic and melodic patterns (see Examples 1a, 1b and 1c). 